\title{
Research on Operating Mechanism of Ocean Energy Industrial Technology Innovation System
}

\author{
Yingying Ding \\ Innovation and Entrepreneurship College, Harbin University of Commerce, No.138 Tongda Street, \\ Daoli District, Harbin, Heilongjiang Province, China \\ 18714509769@163.com
}

\begin{abstract}
Keywords: Technology Innovation; Innovation System; Operating Mechanism; Ocean Energy Industry

Abstract. The ocean energy industry, as one of China's emerging industries, is the key development goal proposed in China's $13^{\text {th }}$ Five-Year Plan. Compared with foreign ocean technology, there is still a lot of space for development of China's ocean energy industry. Taking the ocean energy industrial technology innovation system as the research object, this paper explores the operation relationship between the innovation subjects, and constructs an innovation system model, so as to provide reference value for the development of the ocean energy industry.
\end{abstract}

\section{Introduction}

Under the condition of market economy, any enterprise, organization, industry or region, as an economic community, is a cell of socioeconomic organism, and needs certain mechanisms to promote it. This mechanism is called the operating mechanism. The operating mechanism of the ocean energy industrial technology innovation system is the internal function and operation mode for industry's continuous pursuit of innovation. At the present stage of China's market economy environment, China's ocean energy industry is still a strategic emerging industry, and all internal functions of the industry should be in constant motion. An effective operating mechanism of technology innovation system is the core of linking each component of the technology innovation system, and in case of lacking operating mechanism, the technology innovation system will face the risk of collapsing at any time.

\section{Operation Process of Ocean Energy Industrial Technology Innovation System}

With the introduction of technology innovation behavior, technology innovation activity enters into the stages of development and implementation. The innovation activity is not automatically carried out by people and funds. It depends on certain social organizations. While research institutions, universities and technical enterprises become the basic organizational units of innovation activities, innovation activities also require certain material and technical conditions to support them. The policy environment and legal system guarantee provided by the innovation supporting subsystem provide guidance, support and management for innovation from the national level. The resource environment such as service environment and financial support can provide market demand for technology innovation activities as well as the source guarantee for funds collection. The infrastructure conditions are the prerequisite and basis for all activities to be implemented. How these supporting resources can be effectively combined with the innovation subjects highlights the importance of coordination mechanism. The coordination mechanism of innovation system is not only to coordinate the relationship among innovation subjects as well as the internal resources of innovation subjects themselves, but also to coordinate the relationship between the innovation subjects and the resources in the innovation supporting system.

When the innovation results are about to emerge in the laboratory or other research sites, the industry has entered into the transformation stage of innovation results. The task of this period is to 
realize the commercial value of technological innovation through the technology market, the third party intermediary service institution or the commercial service institution, and make the physical entities of the ocean energy industrial technology innovation achievements that are formed by applying the innovation environment and innovation resources to innovation subjects known to the society as well as the domestic and foreign markets by exploring various sales channels. The process mentioned above requires certain safeguarding mechanism to ensure the timely transformation of the results, the timely establishment and improvement of the policy environment, the timely feedback on issues arising in the process of innovation to the government, industry, market and society, as well as the sufficient human, material and financial resources at all stages of the entire innovation activity. In this period, in addition to the transformation of achievements, another important task is to sum up the experience of innovation at this stage, tap new innovation points, launch a new round of innovations as soon as possible, put new innovation behavior into practice, and enter a new round of technological innovation cycle. Such a positive cycle one the one hand can improve the technology innovation ability of China's ocean energy industry, and on the other hand can make our country occupy the commanding point of technological innovation in the ocean energy industry as soon as possible, and enhance international competitiveness. At this operation stage, the safeguarding mechanism is the most critical factor, and the contribution of the momentum mechanism, development mechanism and coordination mechanism is relatively lower.

The innovation subject is the foundation of the ocean energy industrial technology innovation system and also the source of the technology research and development of the entire innovation system. It is responsible for the whole process of the ocean energy industrial technology innovation system from the germination of innovation consciousness to the achievement of innovation output, covering resource allocation, $R \& D$ personnel selection, incentive mechanism and other aspects. The innovation subject is the prerequisite for the survival and development of China's ocean energy industry, as well as the key link to cultivate and improve the core competitiveness of China's ocean energy industry. It mainly includes the following aspects:

(1) Relationship between enterprises and colleges and universities

Enterprises are important actors in the technology innovation activities carried out by China's ocean energy industry, and every research and development activity in an enterprise is inseparable from those with certain professional knowledge and skills. In the ocean energy industrial technology innovation system, when the external environment changes and needs new products and new technologies urgently, the enterprise is the subject that receives the information feedback the quickest when the market demand changes, and the research and development of new technology are promoted in enterprise innovation layer through the facilitation of power mechanism. Colleges and universities are the most important channels for transferring professionals to enterprises, and the flow of skilled personnel is realized between enterprises and universities through technical research and development cooperation. On the one hand, enterprises can provide internships, research funding and other convenience to universities through sponsorship and other measures to strengthen enterprises' awareness of recruiting talents; on the other hand, college students have enhanced their own social practice experience by taking part in the daily operation and management of enterprises. In addition, many university teachers have established their own companies, and by integrating internal resources of universities and drawing on the research results of professionals, they have derived many high-tech related small companies from within universities. All these aspects are conducive to the transformation and diffusion of China's ocean energy technology, and the acceleration of the chain reaction of ocean energy technology innovation activities.

(2) Relationship between enterprises and scientific research institutions

Compared with institutions of higher learning, scientific research institutions have more advanced 
infrastructure and more professional technical research and development personnel. If technological innovations are compared to commodities, enterprises are the main place to realize their commercial value, and the scientific research institutions are the laboratories that make them happen. In order to pursue the greatest profits brought about by commodities, enterprises will not pay too much attention to the research and development of innovation achievements, but will pay more attention to the market share and profit space brought by innovation achievements. The scientific research institution is an institution engaged in the research and development of science and technology, and it provides feasible technological research results to enterprises through repeated experiments and research of professionals in the laboratory. Enterprises and scientific research institutions, with their respective advantages, perform their respective duties, and stabilize and perfect the market for technology innovation. At the same time, enterprises and scientific research institutions save costs for each other, enterprises omit the research and development process of technological innovation and realize the commercialization of innovation results directly; scientific research institutions omit the marketing process of technological innovation results and accelerate the commercialization of innovation results. In the ocean energy industrial technology innovation system, a technical alliance of enterprises and research institutions reached through cooperation, on the one hand saves costs for repeated work, on the other hand reduces the risk of market fluctuations, and jointly safeguards the coordinated development of technology market.

\section{(3) Relationship between universities and scientific research institutions}

Compared with universities, scientific research institutions are more professional places to carry out technical research and development activities. The common feature of both is that they can deliver high-tech talents to enterprises. The innovation relationship between them is embodied in the exchange of talents and technology, universities provide innovative talents to scientific research institutions, and research institutions provide innovative research and development technologies to universities. For part of the research and development projects in ocean energy, the State Oceanic Administration of People's Republic of China will cooperate with universities, for example, the State Oceanic Administration of People's Republic of China, in collaboration with Harbin Engineering University, completed the 2012 ocean renewable energy special funds project "Integration of ocean energy development and utilization technical standards and specifications". The two sides used their own advantages to complete the corresponding task, Harbin Engineering University published excellent papers related to the project with a wealth of theoretical advantages, and the State Oceanic Administration launched experiments on technological innovation by means of advanced technology research and development equipment. Through the transfer of staged results and the exchanges of technology and information, they jointly realize the achievements of technology innovation.

The innovation supporting environment is the guarantee of the ocean energy industrial technology innovation system, and has the characteristics of openness. It can provide material and information communication for innovation subjects, and has dual function of restraining and promoting innovation subjects. The main contents are as follows:

\section{(1)Relationship between government and industrial sector and innovation subjects}

The relevant regulations of the government and industry sectors play an important role in guiding and supporting the technological innovation activities of enterprises. The government and industry sectors will give preferential policies to the industries that need to be supported in the process of national economic development, provide certain support on tax policies, corporate subsidies and risk management for enterprises with innovative potential or strong innovation ability, and create a convenient environment for innovation through public policy services. At the same time, the continuous feedback of information in the process of enterprise innovation is also a necessary 
condition for the government to strengthen financial input. Through the continuous feedback of information, the government and industry sectors can pay attention to the innovation status of enterprises in a timely manner, timely urge enterprises to change innovation policies, and create the greatest technological leap for market economy development.

\section{(2)Relationship between innovation auxiliary institutions and innovation subjects}

Innovation auxiliary institutions mainly refer to financial institutions and intermediaries. Financial institutions and intermediaries provide guarantee for technological innovation activities in enterprises, scientific research institutions and institutions of higher learning through the circulation of resources among enterprises, scientific research institutions and institutions of higher learning. Financial institutions make up for the lack of funds in the process of technology innovation by enterprises, scientific research institutions and institutions of higher learning in a timely manner, and provide financial support channels for the smooth development of innovation activities. The intermediary agency is responsible for the commercial operation of innovation achievements, and ensures the successful commercialization of innovative technology achievements. Financial institutions and intermediaries run throughout the process of technological innovation activities, supporting innovation subjects for the successful completion of innovation activities, and meanwhile providing new business activities for innovation subjects.

\section{(3)Relationship between other supporting environment and innovation subjects}

The innovation subjects provide human and material resources for the ocean energy industrial technology innovation system, the innovation support agencies provide financial resources and commercial operation support to the ocean energy industrial technology innovation system, and all these activities need to be generated and developed in the context of external environment such as macroeconomic environment, legal and political environment. The demand of the ocean energy industrial technology innovation system for manpower, material resources and capital will change with the changes of external environment. On the contrary, the innovation consciousness among innovation subjects such as enterprises, institutions of higher learning and scientific research institutions influences the external environment. The development of technology innovation activities of the innovation subjects depends on the legal and political environment, and financial institutions and intermediaries are closely related to the macroeconomic environment. Moreover, keeping abreast of latest developments of ocean energy industry in current domestic and international markets can help maximize the commercial value of technological achievements.

\section{Conclusion}

The operating mechanism is the key to the ocean energy industrial technology innovation system. Like any industry, the operating mechanism is the blood for industrial development, linking innovation subjects and innovation supporting environment closely, and the three are inseparable. The effective operation of ocean energy industrial technology innovation system depends on the functioning of subsystems within the industry and the coordination among subsystems. All subsystems within the system coordinate and cooperate with each other, and the operating mechanism can be used to bridge the subsystems to cross system constraint under the premise of ensuring efficiency. Each subsystem with its unique resource advantages coordinates with each other and promotes the system to run in an orderly and coordinated direction. The operating mechanism acts or reacts to the innovation subject subsystem and the innovation supporting subsystem within the entire technology innovation system, and forms the chain cycle with the innovation subject subsystem and the innovation supporting subsystem throughout the industry's entire technology innovation cycle. The various mechanisms within the cycle are scattered in all aspects of the innovation process, and become an important part of the ocean energy industrial 
technology innovation system, which plays a decisive role in smoothly carrying out innovation activities within the innovation system.

\section{Acknowledgements}

The paper is Supported by National Natural Science Fund of China (71602042)、Philosophy and Social Sciences Project of Heilongjiang Province(17JYC146) and Harbin University of Commerce in-station Postdoctoral Scientific Research Support Project(2017BSH031) and 2017 Heilongjiang Province Common Colleges and Universities Young Innovative Talent Training Plan（UNPYSCT-2017202）.

\section{References:}

[1] JAN W POST, HUBERTUS V HAMELERS, CEES J BUISMAN. Energy Recovery from Controlled Mixing Salt and Fresh Water with a Reverse Electrodialysis System[J]. Environ. Sci. technol, 2008:5785-5790.

[2] Chul Hee Jo, Kang Hee Lee \& Yu Ho. Recent TCP projects in Korea[J]. Technological Sciences, 2010, 53(1):57-61.

[3] Charles S. C.. Measurement of the Ocean and Coastal Economy: Theory and Methods [R]. National Ocean Economics Project of the USA, 2011, 3(11):104-114.

[4] Manabu TaKao. A Twin Unidirectional Impulse Turbine for Wave Energy Conversion[J]. Journal of Thermal Science, 2011, 20(5):394-397.

[5] Luo Xingting, Zhang Weikun. Construction of technological innovation system of Marine new energy industry and policy guarantee [J]. Resource development and market, 2014, 33 (07) : 789-795.

[6]Zhu Yongqiang, Wang Xin, Jia Lihu, Xu Dan, Yang Mingzhou. The role of government in the development of Marine energy industry in China [J]. Marine development and management, 2016, 33 (02) : 14-17.

[7]Zhang Jing, Han Limin. A review of the development of Marine strategic emerging industries in coastal countries [J]. Journal of the Marine college of zhejiang (humanities edition), 2015, 32 (01) : 12-17.

[8] Liu Kun, Han Limin. Research on the formation mechanism of Marine strategic emerging industries [J]. Agricultural economic problems, 2014, 33 (12) : 90-96.

[9] Liu Ming, Wang Di. The development status of strategic Marine emerging industries and 2030 outlook [J]. Contemporary economic management, 2014, 34 (04) : 62-65. 